\title{
Language specific bootstraps for UG categories*
}

(PREFINAL VERSION Appeared in: The International Journal of Bilingualism 9-2 (2005)

\begin{abstract}
This paper argues that the universal categories N/V are not applied to content words before the grammatical markings for reference $\mathrm{D}$ (eterminers) and predication I(nflection) have been acquired (Van Kampen 1997, contra Pinker 1984). Child grammar starts as proto-grammar with language-specific operators and category-neutral content words $\mathrm{X}^{\mathrm{o}}$. The first content words are used as proper names with topic-intention and as brand names with characterizingintention. The language-specificity of early operators may be illustrated by the use of whpronouns (what/where?) in English versus the use of illocution particles (nou/denn?) in Dutch/German child language.

Subsequently, deictic operators for topic are regularized as $\mathrm{D}^{\circ}$ and deictic operators for comment as $\mathrm{I}^{\mathrm{o}}$. These functional categories are the bootstraps for category assignment $<+\mathrm{V}>$ and $\langle+\mathrm{N}\rangle$, as a subdivision of the lexicon. The generalized conclusion is that languagespecific systems are not acquired due to a common UG entrance. They rather are highly frequent language-specific bootstraps that coax the child into an adult system that eventually fits UG principles.

The operators in proto-grammar are situation-related, whereas the functional categories $\mathrm{I}^{\mathrm{o}} / \mathrm{D}^{\mathrm{o}}$ are highly sensitive to syntactic context. This explains why, in a bilingual situation, a language switch in the context-free operators will be relatively easy. A language switch in functional categories, by contrast, will have a reflex on the syntactic context and be less easy.
\end{abstract}

\subsection{Introduction.}

It is a common position in generative acquisition studies to accept Chomsky's view that language universals are a priori inherent in the human mind. Children would not need to discover and learn grammars. Development in child language would be more a matter of biological maturation. Language universals would be inborn in the human mind. That might cause grammar to grow into the mind almost automatically under the slightest of provocations. Generative grammarians guided by this view of an a priori grammar have often drawn far-reaching conclusions about the structure of early child language. Consider the three examples of child language in (1).
a. where daddy go?
(English)
(Rizzi 1994) move wh/preliminary illocution structure (CP)
b. (I) wanna bagel!
(English)
pro-drop/preliminary predication structure (IP)
c. ich hab ein grossen Ball (German)
(Hyams 1986)
(I have a big ball)
$\mathrm{V}$-second/preliminary argument structure (CP-IP-VP)
(Poeppel \& Wexler 1993)

The analysis of such examples has been considerably refined and elaborated over the years following the articles I refer to in (1). I will not go into that history here, but rather be concerned with the general inference frame of such proposals (section 1.1). Let me call it the search for UG as a set of a priori principles. Subsequently, I will present an alternative view, the derivation of UG principles from structural acquisition steps. The opposition between these two research programs is relevant for bilingual language acquisition.

\footnotetext{
* I would like to thank Elma Blom, Peter Coopmans and Arnold Evers for their very valuable and often extensive comments. I am grateful to Aafke Hulk and Elisabeth van der Linden who gave me the opportunity to present this paper to the critical audience at Tempe Arizona.
} 


\subsection{UG as the input to the acquisition process}

Rizzi (1994) claims that wh-elements in early child English originate from movement and include a CP illocution-structure, cf. (1)a. Content questions mark the questioned argument/adjunct by means of a wh-pronoun. The $<+w h>$ marked constituent is adjoined to the beginning of the sentence outside of the usual argument structure. The argument structure must remain empty in the position for the corresponding $<-w h>$ variant. The wh-marked questions appear in very early child language as in (2).

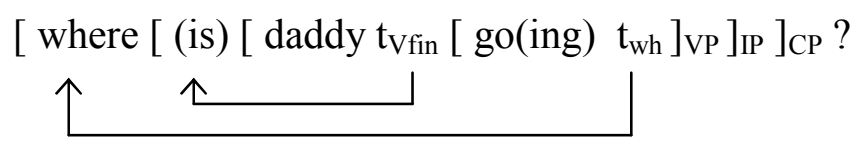

The utterance in (2) led to the following deduction. The wh-element signals a question in the adult language by its relation to the empty position $t_{w h}$ (wh-trace) in the argument structure. The effective use of the wh-element needs no further explanation if we were to assume that $<+$ wh $>$ in child language may as well relate a non-argument position with an argument position. The appearance of the wh-element may show how the child from the very beginning on is guided by awareness about predication (IP), argument structure (VP), illocutionary structure (CP) and wh-movement. Later proposals introduced split CP structures and the considerable expansion for this type of approach (Rizzi 2002).

Hyams (1986) claims that finite verbs in early child English project an IP predicationstructure. Adult English, and other so-called non-pro-drop languages like German/Dutch, require that each finite verb be construed with a spelled-out subject constituent. This property is lacking in early child language. In early child language, one is more likely to find utterances like (I) wanna bagel! (that) is bear, where the material between the brackets has not been realized. This seems to correspond with the situation of the so-called pro-drop languages. The pro-drop languages do not accept non-emphatic personal pronouns in the subject position. Italian is an example. Speakers of pro-drop languages know very well what subject is implied by the context and/or the verbal agreement. So, it has been proposed that all languages are under the sway of the EPP (Extended Projection Principle), a universal grammatical principle that requires predicative structures to be extended such that they must contain a subject position (Chomsky 1981).

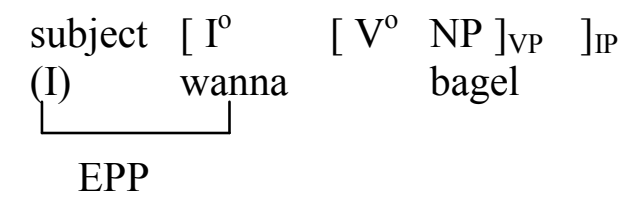

The EPP may or may not allow pro-drop. Suppose now that predication and its EPP are not learned, but inborn. It only happens to be that early child language has not yet been informed by the input whether the target grammar is or is not pro-drop. The assumption in Hyams (1986) is that the pro-drop property is the default option. This seems to have two implications. In the first place, predication structures, that is predicates and their subject obligation, are not learned but automatically present. In the second place, language acquisition consists only in perceiving certain typological variants that happen to be more marked. Later revisions followed (see Hoekstra \& Hyams 1998), but the basic idea remained: early predication structure is defined by the EPP.

Poeppel \& Wexler (1993) claim that finite verbs in early child German originate from movement and project a CP illocution-structure. V-second languages, all Germanic languages except English, take care that the first or second position of each non-subordinated sentence 
(the root sentences) is occupied by the finite verb. The other verbs - past participles and infinitives - appear more to the right. In Dutch and German they are even assigned to the predicate final position. The usual generative analysis assumes that the Dutch/German verbal predicates are head-final (Object-Vfin) and that root sentences get an additional marking. The finite verb in root sentences is moved from its predicate final position into a position on the left, where it has operator scope over the illocution.

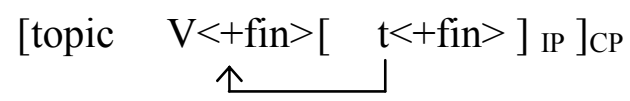

One may assume that root predicates differ from subordinate predicates by having illocutionary value. When do children realize the scope function of the finite form? Very early, it is claimed in Wexler (1998). Finite verbs appear from the beginning on and they are in the scopal left-headed position. The conclusion might be that the root transformation Vsecond is immediately present, even if not always realized. The child spots immediately that the predicative head in final position is moved into the operator position if it is a finite verb. This conjecture is supported by the observation that children hardly make mistakes with the use the finite verb. They need not learn that illocutions are marked by the finite verb in the operator position. They only need to learn that such a marking is obligatory. Later revisions by Wexler (1998) show how the same idea fits in a minimalist framework (Chomsky 1995).

This deductive type of reasoning is possible if one assumes that the learner was somehow aware of the common grammatical distinctions and in addition that he/she had little trouble in applying such knowledge to incoming language specific messages. The child is already aware of the need to have a subject-predicate structure, the possibility to apply movements, the existence of some underlying argument order, an underlying position of the verb itself, and of course the syntactic category features that are obviously involved $<+$ wh $>,<+$ fin $>,<+$ pro $>$, $<+\mathrm{V}>,<+\mathrm{N}>, \mathrm{CP}$, IP and VP. This is quite a lot of a priori distinctions. It seems to me that this view implies two general considerations. In the first place, early acquisition steps are based on grammatical distinctions that are fairly universal maybe because they are very inborn. In the second place, it would be difficult to imagine how appropriate acquisition procedures could reach in time all the syntactic categories, predication forms or the underlying argument structure needed for the analyses just mentioned. The latter consideration (the 'how else' argument) can be counterbalanced by 'an adult overinterpretation of early child language should be avoided'. This is the point of view I will develop in the next sections.

\subsection{UG as the outcome of the acquisition process}

My alternative research program in (5) maintains a generative orientation, but rejects a free postulation of grammatical a priories.

(5) a. Construct grammars that account for the successive distributions in child language.

b. Derive the growing complexity of these grammars as an input-controlled acquisition.

As far as wh-movement and pro-drop are concerned, a longitudinal picture shows that these will not appear systematically before systematic D-marking and the introduction of free (discourse) anaphors ( $3^{\text {rd }}$ person pronouns). See Van Kampen to appear. Earlier examples must and can be explained by means of an alternative system, namely proto-grammar, as I will show below. The same holds for early V-second, see Evers \& van Kampen (2001) for an exposition. 
I would like to present the orientation on the order of the learning steps as the learnability research. The learnability research implies in the first place an insistence that natural grammars are designed to be learned by children. The learnability perspective holds for language-specific arrangements as well as for grammatical universals. Properties like whmovement, obligatory subject and verb-movement, may be fairly universal, but that must follow from the fact that they are highly learnable once they are present in the input. This is somewhat different from the common point of view that something need not be learned if it is universal. Wh-movement in Dutch corresponds with a universal property, but it is certainly learned in the sense of showing a slow but structured adoption to input properties (Van Kampen 1997). By 'structured' I mean that the order of the acquisition steps follows from the organization of the grammar, rather than from neurology. It a characteristic for learning a system that you must master some of its features before you master other features, irrespective of your neural make-up. In the second place, the learnability research implies the focus on quantified longitudinal evidence about individual children. Averaging over groups of children not only blurs the speed of the individual acquisition steps, it blurs as well an appropriate analysis of the preceding stages.

I cannot immediately provide reinterpretations for all arguments in the literature that UG conditions must be innate. Yet, this paper will further argue the points in (6).

(6) a. There is some initial grammar before the acquisition of systematic I-marking and Dmarking. Following a suggestion by Lyons (1977, 1979), I will indicate that initial grammar as proto-grammar Proto-grammar is based on illocution operators for simple pragmatic language games \{more, no, want, is, that, there\} and lexical content elements \{bear, drink, car, nice\}.

b. The child starts the acquisition of adult grammar with predicate marking ( $\mathrm{I}^{\mathrm{O}} / \mathrm{Aux}$ ) versus argument marking ( $\mathrm{D}^{\circ} /$ Case). The source of that development is a grammatical marking of topic-comment intentions as IP structures. For example bear running/nice becomes the bear is running/nice. It is a remarkable fact that copula insertion represents the overwhelming majority of predicate marking, see Van Kampen (2001a).

c. The acquisition of systematic I/D-marking is the key to several further developments such as the acquisition of the category distinction between (universal) $\mathrm{V}$ and $\mathrm{N}$.

$\mathrm{d}$. The illocution operators in proto-grammar like \{more, no, want, is, that, there\} are highly situation-related whereas the functional categories like the various types of $\mathrm{I}^{\mathrm{o}}$ and $\mathrm{D}^{\circ}$ are highly sensitive to syntactic context. This explains why in a bilingual situation, a language switch in the context-free operators will be relatively easy. A language switch in functional categories, by contrast, will have a reflex on the syntactic context and be less easy. A language switch on the functional category represents a code-switching, whereas this does not hold for a language switch on the pragmatic illocution operator or the lexical content elements.

\subsection{Outline of the paper}

Proto-grammar is based on combining operators for simple pragmatic language games with lexical content elements. I will exemplify that distinction in section 2 . The claims I make are in line with the analyses by Lebeaux (1988), Radford $(1990,1996)$ and Jordens (2002), but I add the perspective that UG properties are the outcome rather than the source of structural acquisition steps. The lexical content elements are in the proto-grammar category-neutral between N/V/A/P. The wh-elements and the finite elements in very early child language are of a different kind, but they fall nevertheless within the scope of proto-grammar. They have at that moment all properties of the context-free operators. They do not necessarily need deep 
properties from UG syntax. The argumentation will be based on examples from English and Dutch child data in CHILDES (MacWhinney 1991).

The first functional category that is undeniably acquired, at least in Dutch and French, is Imarking, the marking of a predicate by a factor $<+\mathrm{I}>$ \{copula, auxiliary, modal, finite morphology (section 3) ${ }^{1}$ I-marking is followed by the acquisition of D-marking, the marking of arguments by a factor $<+\mathrm{D}>$ \{article, demonstrative, possessor, quantifier (section 4). By a functional category I mean an element that imposes syntactic structure on its environment, whereby its lexical content is absent or standardized (Emonds 1985: 191). Both I-marking of predicates and D-marking of arguments are examples of marking by a functional category. The universal lexical categories $<+\mathrm{N}>$ and $<+\mathrm{V}>$ are acquired from the language specific Dmarking and I-marking (sections 3 and 4). Note how this presumes an acquisition path from a syntactic distinction (IP/DP) towards the lexical category distinction $(\mathrm{V} / \mathrm{N})$, playing down the cognitive distinction between events and things. It is a reversal of Pinker's bootstrapping scenario, which moves from a cognitive distinction (event/thing) towards the lexical classes (V/N) before arriving in syntax (IP/DP), see Van Kampen (1997, 2001b).

As a matter of fact, bilingual acquisition of grammars is possible without a fatal degree of confusion. One of the reasons must be that the functional categories in each grammar are tied up with corresponding features in the lexical items of the specific grammar (section 5). A language switch in the functional category implies immediately selection from the corresponding lexicon. It is a code-switching. A mere selection of a different lexical content element has no such consequences. It remains a context-free local language mix. The situation in proto-grammar is different. Proto-grammar contains no functional categories, as will be argued below. Consequently, code-switching is not possible during that stage of development and language mixing will be relatively easy, certainly for the situation-bound operators and also for the category-neutral content elements.

\subsection{Proto-grammar}

There is a period in child language when utterances are at most binary sign combinations. I use the Saussurian word 'sign' here as a hedge, since quite a few of these elements will be reanalyzed later on as morphological or phrasal constructs, e,g. wanna becomes want to or want a. See Bellugi (1967), Van Kampen (1987, 2001b), Hoekstra \& Jordens (1994) and especially Jordens (2002) for striking examples. ${ }^{2}$

The content elements in this period do not carry by themselves a referential or a predicative intention, nor are they marked by some $\mathrm{I}^{0}$ for predication or some $\mathrm{D}^{\mathrm{o}}$ for reference. Such intentions are for the sympathetic listener to find out. I assume this is the period that Lyons (1977:649, 1979:90) had in mind when he suggested that child language might have proto-predication as a forerunner of predication and also that child language might have proto-reference as a forerunner of reference. I propose to give more grammatical and empirical substance to these ideas.

\footnotetext{
${ }^{1}$ That means that an account of the $<-$ fin $>$ utterances in early child language includes not only later verbal predicates, so-called Optional 'Infinitives', but also, and crucially, later non-verbal predicates like 'daddy nice' or 'bear in (the) zoo'. See Van Kampen (1997) for this generalization.

${ }^{2}$ For instance, the Dutch children Jasmijn and Andrea use illocution operators like kannie (can't) mawel (mayindeed), doemaa (do-please), magikke (may-I) (Jordens 2002).
} 


$\begin{array}{lll}\begin{array}{l}\text { Proto-grammar } \\ \text { proto-reference } \\ \text { "topic naming" }\end{array} & \begin{array}{l}\text { Grammar } \\ \text { reference (systematic D-marking) } \\ \begin{array}{l}\mathrm{D}^{\mathrm{o}}+\mathrm{X} \\ \text { proto-predication } \\ \text { "characterizing comment" }\end{array}\end{array} \quad \begin{array}{l}\text { predication (systematic I-marking) } \\ \mathrm{I}^{\mathrm{O}}+\mathrm{X}\end{array}\end{array}$

Let predication and reference be distinctions that can be defined only in connection with a grammar. Early child language may use a sign to characterize some salient aspect of the situation. Let me call that proto-predication rather than predication. Let the notion predication be applied only if the characterizing signs are systematically marked by one of the $\mathrm{I}^{0}$ devices, such as \{a copula, a modal, an auxiliary verb or finite morphology\}. The same recipe applies to reference. Early child language may use a sign to name some salient aspect of the situation. Let me call that proto-reference rather than reference. Let the notion reference be applied only if the naming signs are systematically marked by one of the $\mathrm{D}^{\mathbf{o}}$ devices, such as an article, a possessive, a demonstrative or a case marking\}. The functional categories $\mathrm{I}^{0}$ and $\mathrm{D}^{\circ}$ are second order elements. They create and mark a syntactic order for content elements.

\subsection{Category-neutral content signs $X$}

Bear in (8) may be regularly used by the child without a copula $\mathrm{I}^{0}$ or a marker $\mathrm{D}^{0}$. It may be used as a situation-bound topic and proper name (proto-reference) or as a situation-bound characterizing comment (proto-predication). ${ }^{3}$ The switch between naming and characterizing signs is not yet a matter of syntactic categories but a matter of pragmatic intention only.

\section{Pragmatic switch of intention for category neutral $X$}

a. proto-reference

$$
\text { X }
$$

beertje

(bear)

(is a proper name with fixed reference, i.e. name for the child's cuddly bear) b. proto-predication<smiles>[Y]</smiles>

beertje (bear) (is a characterization)

The category neutral $\mathrm{X}^{0}$ survives in binary utterances with two content signs (Van Kampen 1997, 2001b), see the examples in (9). ${ }^{4}$

\footnotetext{
${ }^{3}$ I make a sharp distinction between the situational context of a sentence versus its (linguistic) discourse context. The situational context is in principle available to the child, without additional grammatical devices. The discourse context is in my view not accessible to the child until there is the systematic application of $\mathrm{D}^{\circ}$ and $\mathrm{I}^{\mathrm{o}}$ (cf. Hoekstra \& Hyams 1995, 1998)). These are deictic devices of anaphoric marking. They may relate the sentence to previous utterances. In the same vein, I distinguish situation-bound deixis, i.e. gesture sustainable identification by pointing (that/it; here/there; now/then), from grammatical anaphoric deixis, i.e. the grammatical marking by deictic functional categories $\mathrm{D}^{\circ}$ and $\mathrm{I} / \mathrm{T}^{\mathrm{o}}$ ( \pm def; \pm past).

${ }^{4}$ The analysis of category-neutral binary structures in child language was elaborated in Van Kampen (1997) for the $\mathrm{Y}-\mathrm{X}^{\mathrm{o}}$ patten in (9) and for $\mathrm{X}^{\mathrm{o}}$-Y patterns like read bookletffrom daddy. It is argued there that the order headfinal or head-initial might be deduced by the child from stress patterns in the input. See also Tracy (2002), Gawlitzek-Maiwald \& Tracy (this volume).
} 

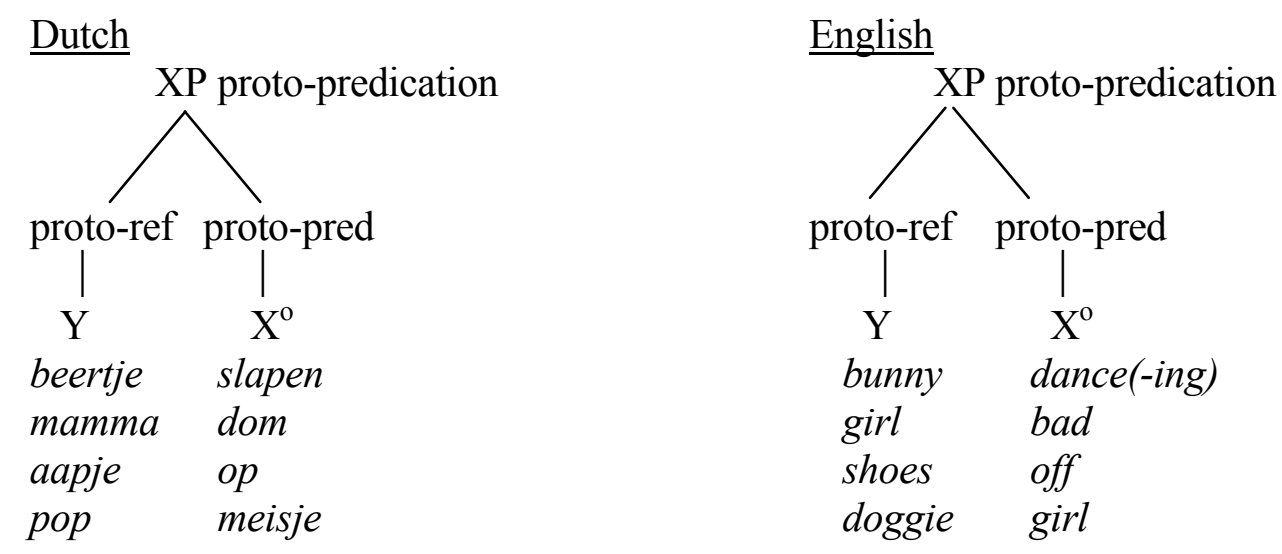

I propose to characterize (9) as topic-comment structures that function as proto-predications. The utterance stress is usually on the second element, the proto-predicate. The two-word utterances are in the present view category-neutral. Lexical categories $<+\mathrm{V}\rangle$ and $\langle+\mathrm{N}\rangle$ cannot be assigned before there is an idiomatic relation with a predicate marker $\mathrm{I}^{\mathrm{o}}$ or a reference marker $\mathrm{D}^{\circ}$. The same reserve is recommendable for the terms subject and predicate. Children may have sensible reactions, but interpreting them by means of formal grammatical understanding is premature. The subject-predicate relation follows from the form-based $\mathrm{I}^{\mathrm{o}} / \mathrm{D}^{\mathrm{o}}$ devices of real grammar. These are a-typical for proto-language. The proto-predicate $\mathrm{X}^{\mathrm{o}}$ is not systematically marked by some $\mathrm{I}^{\mathrm{O}}$, whereas the later predicate is. Systematic non-expression of a distinction is best explained by systematic absence of the distinction.

\subsection{Pragmatic operators $F$}

Category neutrality also holds for another type of binary utterances. This type combines a category-neutral content sign with a pragmatic operator $\mathrm{F}^{\mathrm{O}}$ (Van Kampen 1987, 2001b). ${ }^{5}$ The operator marks the utterance for some fixed use in a language game, see (10). There is a presentational/naming in (10)a, a wish in (10)b, a sign for conversational turn taking in (10)c, a denial in (10)d, a refusal in (10)e, a possession claim in (10)f and a content question in (11) (Van Kampen 2001b). ${ }^{6}$ The operator appears either in left-handed position (operator $+X$, see (10)) or in right-handed position (X+operator, see (11)a). Some of the operators seem to take both positions, but not without a different pragmatic intention. See for lists of examples also Braine (1963), who labeled them pivots, Roeper (1992) and Jordens (2002), who presents a similar operator analysis for early child Dutch. None of these studies propose categoryneutrality, but I do.

\footnotetext{
${ }^{5}$ The use of a category $\mathrm{X}$ is not uncommon as an expository notation. E.g. the operators wanna \{P:up; V:see; $\mathrm{N}: c a r ; \mathrm{A}: t i g h t\}$ and more/no $\{\mathrm{P}:$ up; V:read; N:ball; A:dirty\} in child language are characterized as want $X$ and more/no $X$ in Powers (1996) and Powers \& Lebeaux (1998). It is proposed here that the notation be taken seriously, as in Lyons $(1977,1979)$, and that the categories $\langle+/-\mathrm{N}\rangle,\langle+/-\mathrm{V}\rangle$ be derived later on from discriminating functional contexts.

${ }^{6}$ The various sentence adverbs (nou/nog/ook/even/zo/dus 'now/yet/also/just/so') are quite frequent and subtle means in adult Dutch. They are reduced to a few pragmatic functions in early child language: presentational gesture, emphasis, turn-taker in a conversational exchange (Van Kampen 1997:79f, 2001b, Jordens 2002). For alternative views on sentence adverbials in child Dutch/German, see Powers (1996), Penner, Tracy \& Weissenborn (2000), Gawlitzek-Maiwald \& Tracy (this volume) and for aussi in child French, see Hulk (2001).
} 
(10) Illocution-marked proto-predications (operator + category-neutral content sign)

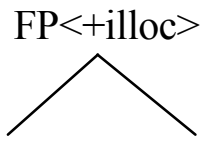

$\mathrm{F}^{\mathrm{o}}$ (operator) $\mathrm{X}$ (proto-pred)

a. is muisje/lief/spelen dat muisje

b. kwil spelen

c. nog/ook op

d. niet lief

e. nee beer

f. ikke muis

(11)

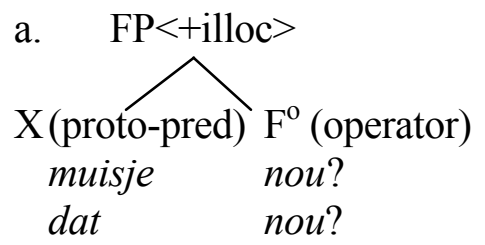

$\begin{array}{ll}\mathrm{F}^{\mathrm{o}} \text { (operator) } \mathrm{X} \text { (proto-pred) } \\ \text { is } & \text { mouse/nice/play } \\ \text { that } & \text { mouse } \\ \text { wanna } & \text { play } \\ \text { more } & \text { on } \\ \text { not } & \text { nice } \\ \text { no } & \text { bear } \\ \text { my } & \text { mouse }\end{array}$

operator for: presentation and naming wish turn-taking denial refusal possession claim

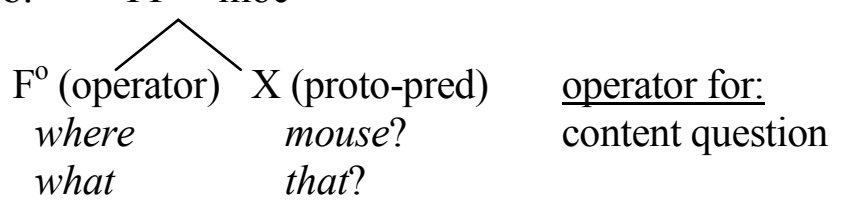

These illocution operators introduce a comment sign. The same is present in the examples in (12) and (13) where the operator functions as an utterance announcer and refers to an entire situation. See for more examples Van Kampen (1997:126, 2001b) and Jordens (2002). ${ }^{7}$

(12) Dutch Sarah (Van Kampen corpus)
a. ditd: hondje weg
$(1 ; 10.5$, week 96)
(this $\partial$ (is) doggie gone)
b. ditдnie: bad zwemmen
$(1 ; 11.15$, week 102)
(this (is) not (in) bath (to) swim)
c. kwi(l): dit mooi
(2;0.17, week 107)
(wanna this beautiful)
d. kan: deur
$(2 ; 5.22$, week 129)
((I) can (open the) door)
e. manie: <ha, ha,ha>
(2;0.22, week 108)
((I) may not (do) $<$ ha, ha, ha)
f. ookd: eten trein
$(1 ; 11.15$, week 102)
(alsod (to) eat (in) train)
g. even: spullen weg
$(2 ; 0.17$, week 107)
(stilld (are) things gone)
h. nog: paardje $^{8}$
(2;1.10, week 110)
('more' (you play) horsie)

(13) English child language
a. that: daddy there
(Daniel 1;8)
b. that's: horsie running
(Nina 2;0.3)
(from Braine 1976)
c. is $\partial$ :
(Adam 2;10)
(Suppes corpus)
d. wanna: lady open it
(Daniel 1;10)
e. no:
lamb have it
(Nina 2;0.24)
(Brown corpus)
(from Radford 1996)
(Suppes corpus)

According to my counts in proto-grammar, the operators tend to have a frequency that is a few hundred times higher than the content signs. I propose that the learning device is sensitive to frequency difference.

\footnotetext{
${ }^{7}$ See for the meta-linguistic use of various operators also Van Kampen (1987), Radford (1990:75f), Hoekstra \& Jordens (1994), Drozd (1995), Powers \& Lebeaux (1998).

${ }^{8}$ nog is often used by the Dutch child in the context where the English child uses 'more'.
} 
(14) Number of occurrences for single items (types) (Dutch Sarah, week 86-150)

a. Illocution operators: between 50-300 tokens

b. Content signs $X$ : between 1-30 tokens

The pragmatic operators are not a kind of functional categories. They can only be defined by means of situation types, whereas functional categories such as articles and copulas can only be defined within syntax. The introduction of the pragmatic operators does not imply either that the abstract syntax of the common generative appraoch mentionned under (1) has now been replaced by complex pragmatics. The distinctions of the pragmatic operators are elementary situation-bound oppositions between roles in elementary games (Wittgenstein 'Philosophische Untersuchungen').

There is something remarkable about the presentational operators in (10)a,b and about the question operators in (11). The presentational operators in (11)a,b are taken from a demonstrative that/this as well as from a copula $i s .{ }^{9}$ These very signs, the demonstrative and the copula in proto-grammar, have a singularizing pointing effect. At a certain point in time, they begin to be added regularly to content signs for topic and comment. As soon as the comment function is systematically marked by Aux $/ \mathrm{I}^{\mathrm{o}}$ and the naming intention by $\mathrm{D}^{\mathrm{o}} /$ case, there is a form-based marking of predication structure and argument structure. Proto-grammar has given way to real grammar.

If one were to accept the distinction between proto-grammar and real grammar, one is bound to reject the claims in (1) that there could be something like early CP/IP/VP structure and early wh-movement, pro-drop and $\mathrm{V}$-second. These are grammatical phenomena that presuppose a full command of I-marking and D-marking. The acquisition facts referred to in (1) are as such not necessarily beyond the scope of proto-grammar. The early wh-element in (11)b is arguably an operator that solicits for some verbal reaction of the conversation partner. The forms that apparently seem to demonstrate early pro-drop, like wanna in (1)b, bear the standardized forms and high frequency marks of utterance operators (see Van Kampen 2003, to appear) The early $\mathrm{V}$-second examples for lexical verbs do not appear with some systematic frequency until the acquisition of auxiliaries in the second position have been acquired (see Evers \& Van Kampen 2001, Blom 2003). A more specific argument against the early whelement as a CP operator is the analysis of wh-movement in Dutch (Van Kampen 1997). Rather than using the wh-element, Dutch proto-grammar uses a sentential adverbial (nou), see (11)a. The same holds for Swedish (Santelmann 1995) and German (Tracy 1994). The whpronoun is not spelled out until after I-marking and D-marking have been mastered. See Van Kampen (1997: ch. 4) for a full analysis. The difference in (11) between early wh-questions in English and early wh-questions in V-second Germanic languages seems incomprehensible unless we assume a far more simple difference in proto-grammar. A stressed sentence adverbial, not present in English, is generalized into a question operator in (11)a. Contrary to the usual generative assumptions, proto-grammar should be free from the later syntactic categories and allow that early wh-elements function as pragmatic operators only.

The next two sections will follow the development from proto-grammar to real grammar for Dutch Sarah (CHILDES, Van Kampen corpus). At the proto-grammar stage, when her utterances are mainly binary sign combinations Sarah is 1;9.10 (week 93). A year later, at 2;9.7 (week 145), she has acquired both I-marking and D-marking.

\subsection{The acquisition of $\langle+I\rangle$ and $<+V\rangle$.}

From the beginning on, Dutch Sarah had some part of the proto-predicates (far less than 10\%) preceded by a clitic-like ' $-s$ ' that reminds of the copula $i s_{<+ \text {fin }>\text {. Also marginally, proto-predicates }}$

\footnotetext{
${ }^{9}$ The fact that copula and demonstrative are morphologically related in some languages (Stassen 1997:99) seems to me plausibly related to this characteristic of proto-grammar.
} 
began with a modal or a finite verb, instead of the unmarked root infinitive, see (15).
a. balweg (ball away) bal ookweg (ball also away)
bal rollen (ball roll)
b. bal sweg (ball saway) bal moet weg (ball must (go) away)

The type of predicate marking exemplified in the $(15) \mathrm{b}$ variants lingers around from the beginning on, but in a marginal way only. From a certain point on, predicate I-marking begins a steep and irreversible rise. Within twenty weeks (weeks 100-120) Sarah's <+fin> predications rise from $10 \%$ to more than $90 \%$, see the acquisition graph in (16) (Evers \& Van Kampen 2001).

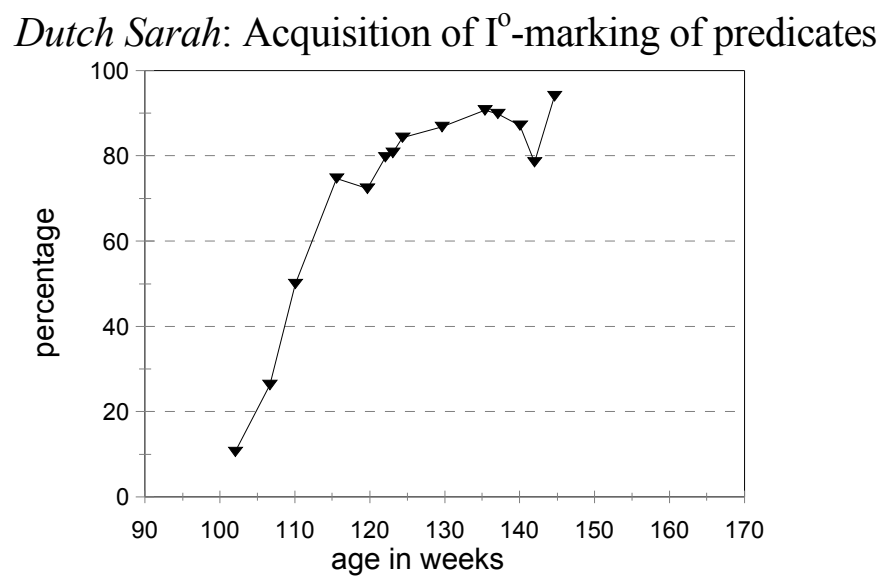

Sentences that realize a finite verb in first or second position in $\geq$ two-word utterances

The rise of the graph for I-marking in (16) follows from two separate developments. Modal operators and the copula appear increasingly as prefixes of comments in the topic-comment utterances. This is followed by the rise of finite lexical (content) verbs. An example of the introduction of the finite verbs is given in (17).
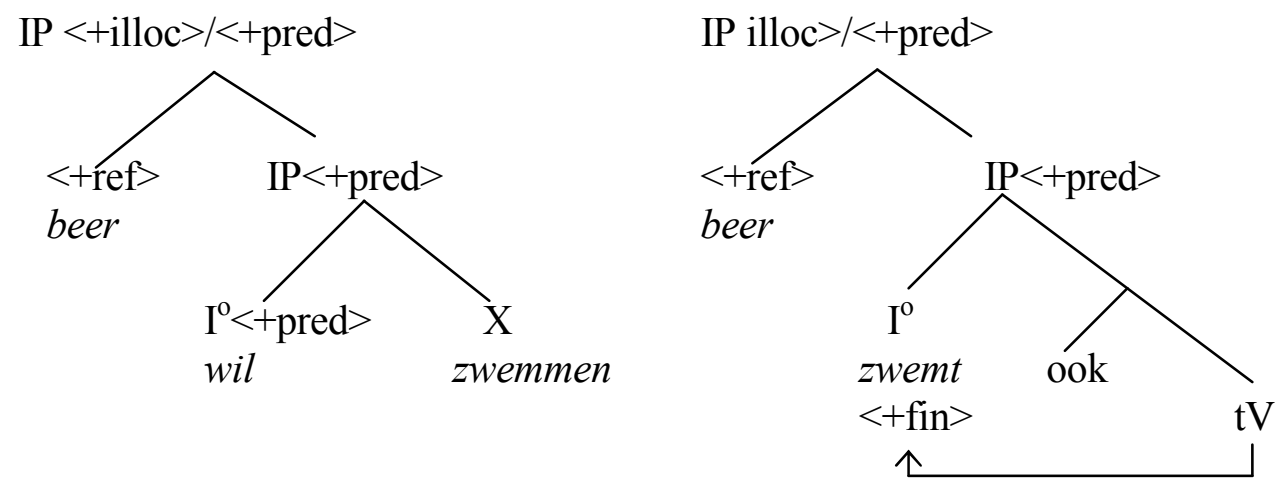

The $\mathrm{V}<+$ fin $>$ movement in $\mathrm{V}$-second Dutch is $\mathrm{C}^{\mathrm{o}}$ attracted. That problem is neglected in (15), but see Evers \& Van Kampen (2001) for a discussion and for references. The rise in $I^{\mathrm{O}}$ marking reflected in the graph is part of a larger phrasal development in (18) and (19). The development in (18) represents the acquisition if the subject-predicate construction.

(18) a. The proto-predicates get systematically marked by $\mathrm{I}^{\mathrm{O}}$

b. Most I-marked comments are accompanied by topics that have a fixed theta-relation \{agent, theme\} 
The acquisition procedure perceives the obligatory presence of such topics and establishes the EPP (all predicates need a subject).

(19) Modal verbs are used as I-markers that need a subject. The use of modals as operators, quite common in proto-grammar, gets marginalized

A clear indication that the modal operators get blocked by the $<+$ fin $>$ interpretation is the first appearance of the personal pronouns $i k / j i j$ (I/you), see (20)b. These appear only marginally in the proto-language. They were present only as subjects 'implied' by the operator, see Van Kampen (to appear). The operator wil/kwil ('wanna') in ((20)a) meant $i k$ wil ('I want') and hoenie meant $i k$ hoef niet ('I don't have to'), cf. (Van Kampen 1997, 2001b, Powers 1996). The same delay was found for the acquisition of je/tu in French (Van Kampen to appear). As soon as the <+fin> interpretation of the modal overrules its former use as an operator, the EPP comes in and there is a need to fill up the specifier position. The $1^{\text {st }}$ and $2^{\text {nd }}$ person are now understood and used as a kind of topic/referent. Soon the personal pronouns are no longer mode-implied elements only. They appear as regular argument options with all predicates. The grammatical situation that results from (18) and (19) allows the constructions to be reinterpreted as the subject-predicate pattern in (20)c.

(20) Dutch Sarah

a. First person operator-implied

\begin{tabular}{|c|c|c|}
\hline kwi(l) uit & (wanna out) & reek 102) \\
\hline kwil-ook boot & ((I) wanna also boat) & (1;9.10, week 93) \\
\hline kan liedje niet & ((I) can song not (sing)) & $(2 ; 0.17$, week 107) \\
\hline iet wassen & ((I) need $\partial$ not wash) & $(2 ; 0.17$, week 107$)$ \\
\hline kleuren & (I-go just color) & $(2 ; 1.10$, week 110) \\
\hline vies & ((I) may indeed dirty) & (2;0.10 diary) \\
\hline 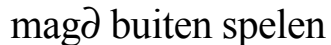 & ((I) mayd (indeed) play outside) & $(2 ; 0.22$, diary $)$ \\
\hline
\end{tabular}

b. First person expressed due to EPP

\begin{tabular}{|c|c|c|}
\hline ik wil jou niet spelen & (I want (with) you not play) & $(2 ; 1.10$, week 110$)$ \\
\hline ik kan die lezen & (I can that read) & $(2 ; 4.27$, week 125$)$ \\
\hline ik hoef niet & (I need not) & $(2 ; 4.2$, week 122$)$ \\
\hline ik ga naar Nienke niet & (I go to Nienke not) & $(2 ; 4.9$, week 123$)$ \\
\hline \multicolumn{3}{|c|}{ Modal as independent predicate } \\
\hline hoef & (I need) & $(2 ; 1.10$, week 110$)$ \\
\hline - & (I want) & $(2 ; 2.18$, week 116$)$ \\
\hline kan niet & (I cannot) & $(2 ; 4.27$, week 125$)$ \\
\hline
\end{tabular}

The common source of the phenomena in (18) and (19) is the reinterpretation of a pragmatic sign for utterance modes as a functional category $\mathrm{I}^{\mathrm{O}}$ for predicative intentions, see (22). The term 'bootstrapping' was introduced by Pinker (1984) for the acquisition of category labels due to cognitive distinctions (thing/event). Here the bootstrap is offered by syntax itself.

\section{Bootstrapping $\mathrm{I}^{\mathrm{O}}$}

Pragmatic intention of commenting a topic

$$
\Downarrow
$$

Comment optinally expressed by a gesture sutainable deictic operator $\mathrm{F}^{\mathrm{o}}$ $\Downarrow$

Obligatory presence of $\mathrm{F}^{\mathrm{o}}$ equals $\mathrm{I}^{\mathrm{o}}$ (predication) and EPP 
The interpretation of the pragmatic intention $<+$ pred $>$ as $<+\mathrm{I}>$ has still another consequence. The $<+\mathrm{I}>$ stands for a hand of various devices, some morphological like <+fin $>$ others syntactical as the copula and the other auxiliary-like elements. Not all elements of the category neutral $\mathrm{X}$ can be combined with all of the $\mathrm{I}^{\mathrm{0}}$ 's. The Dutch copula can be combined with all, but other I-markings are more selective. The three $\mathrm{I}^{\mathrm{o}}$ types ' $\mathrm{X}{ }^{\mathrm{o}}<+$ fin $>$ ' is aan het $X^{\circ}$ (related to the English present continuous) and is/heeft $X^{\circ}<$ past participle $>$ (related to the English perfect) require a subset of $X^{0}$ elements that scholars may recognize as $\left.<+V\right\rangle$. The following rules offer the acquisition context for it (cf. also Blom and Krikhaar 2002).

(23) $\quad \underline{\text { Dutch }}$

a. $\mathrm{X}<\mathrm{lex}>\Rightarrow<+\mathrm{V}>/$ [(is) aan het - ] ('is on the' infinitive)

$/$ [heeft/is ge- - ] (past part. morpheme)

$/[<+$ fin $>] \quad$ (finite verb)

$\underline{\text { English }}$

a. $\quad \mathrm{X}<$ lex $>\Rightarrow<+\mathrm{V}>/[$ is - -ing $]$

b. $\mathrm{X}<\mathrm{lex}>\Rightarrow<+\mathrm{V}>/[$ has/is - -ed]

(24)

lexical $<+\mathrm{V}>$ due to

morphological context

or

lexical $<+\mathrm{V}>$ due to

phrasal context
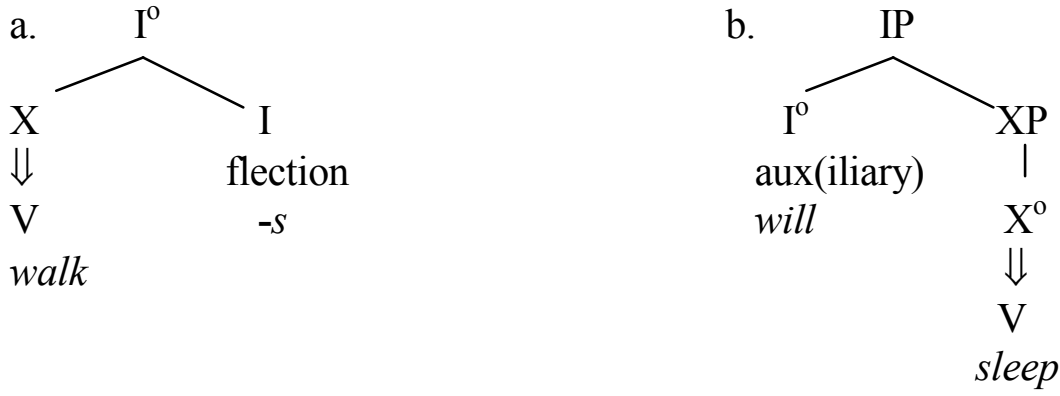

$(25)$

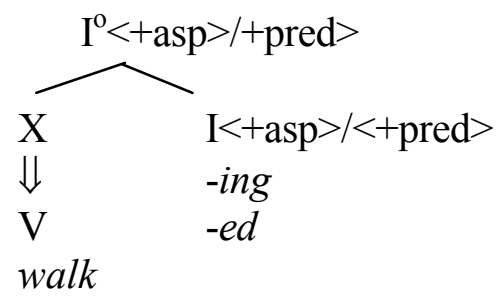

The context sensitive acquisition rules in (24) boil down to the traditional position that $\mathrm{V}^{\mathrm{o}}$ is identified by its paradigm, where paradigm generalizes over periphrastic and inflectional forms. Slightly different, one might say that the category $<+\mathrm{V}>$ is identified by the $\mathrm{I}^{\mathrm{o}}$ categories in its extended projection (Grimshaw 1991). See for a recent analysis of defining N and V in the syntax Marantz (1997). The new perspective here and in Van Kampen (1997, $2001 b$ ) is that this common approach to defining $\mathrm{V}^{0}$ is seen as a bootstrapping acquisition procedure.

The category $<+\mathrm{V}>$ is acquired by an exclusive language specific, but highly frequent context. The assigned $<+\mathrm{V}>$ has further consequences for the learner. $<+\mathrm{V}>$ indicates that a lexical item has access to the full morphological and syntactic paradigm that a grammar may have. 
Usually, psycholinguists are fond of plausible cognitive distinctions to get control over grammatical arrangements. As such, it must be attractive to accept Pinker's (1984) claim that the cognitive distinction between things and actions will lead to lexical categories $\mathrm{N}$ and $\mathrm{V}$. Let me point out that the functional categories I and D have good points as well to be considered as bootstraps, see (26) (cf. Emonds 1985:191).

(26) Functional categories $\mathrm{F}^{\mathrm{o}}$ differ from lexical content elements $\mathrm{X}^{\mathrm{o}}$ by

a. a fixed distribution (order and stress)

b. a high, closed class, frequency

A good point of the present I/D entrance to lexical categories seems to me that the system itself is analyzed as 'learner friendly'.

4.0 The acquisition of $\langle+D>$ and $\langle+N\rangle$

Consider again the constructs in (27) with an illocution operator and a content element. The deictic demonstratives dat/dit/die/deze ('that/this/these/those') for the pointing gesture in presentationals have at first an intonation break. ${ }^{10}$ They cannot be used in a predicative way and are exclusively referential. In 'picture looking' games, or somewhat freer 'naming games' they refer to a thing or person.

\begin{tabular}{llll}
\multicolumn{2}{c}{ presentational } & & \\
deictíc operator $\mathrm{X}$ & & \\
dat & beertje & (that & bear) \\
dat & mamma & (that & mummy) \\
deze & aapje & (this & monkey) \\
dit & pop & (this & dolly)
\end{tabular}

Content signs with a naming function begin to appear with articles in a fashion strikingly similar to the I-marking of the proto-predicates, but 20 weeks later. The insertion of articles $\left(\mathrm{D}^{\circ}\right)$ rises again from less than $10 \%$ to more than $80 \%$ within a period of 20 weeks. See the acquisition graph in (28) (from Van Kampen 2001b, to appear).

\section{Dutch Sarah: Acquisition of $\mathrm{D}^{\mathrm{o}}$-marking of arguments}

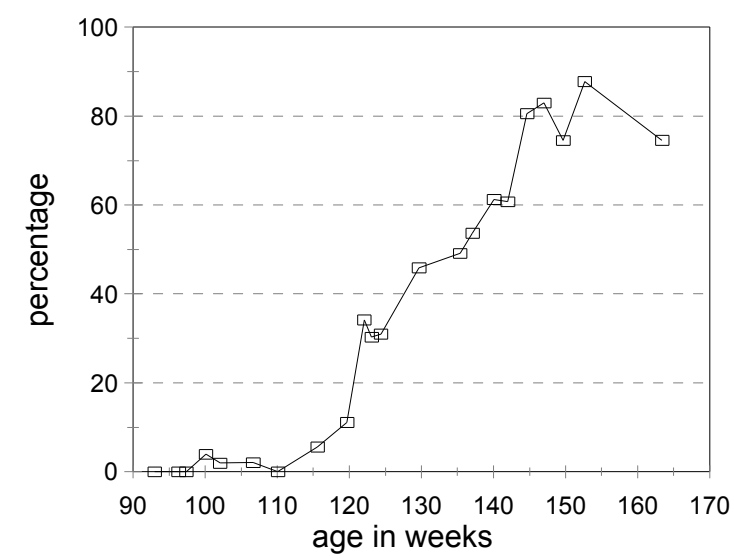

Noun phrases that realize determiners in obligatory contexts in $\geq$ two-word utterances

\footnotetext{
${ }^{10}$ In adult Dutch deze/dit are the proximal demonstratives and die/dat the distal demonstratives; dit and dat are used with neuter nouns. Early child language does not make these distinctions yet.
} 
The rise of the graph for D-marking in (28) illustrates how articles de/een ('the/a') appear as phrasal 'prefixes' of a referentially intended X (first opposition $<+/$-definite $>$ ) and begin the irreversible rise at week 120. An example of the introduction of the article is given in (29).

(29)

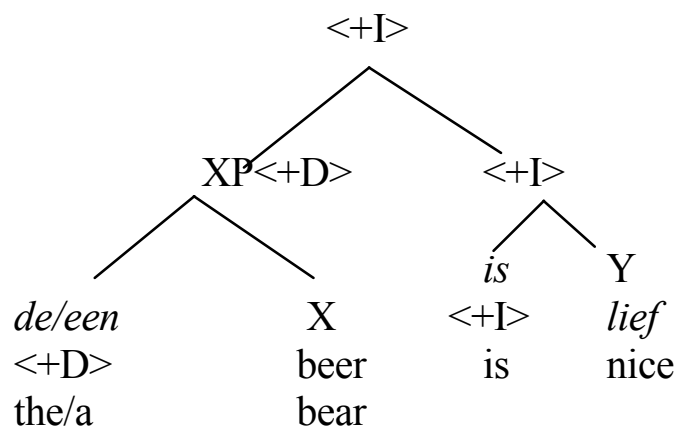

The rise of the D-marking that is is reflected in the graph in (28) is part of a larger development.

a. The proto-reference part of the utterance is marked by $\mathrm{D}^{\circ}$ (a demonstrative or an article)

b. The deictic operator for naming things dat changes into an independent topic/subject demonstrative due to the EPP.

c. The demonstrative dat and the $3^{\text {rd }}$ person pronouns appear in all argument positions. Reference marking is perceived and learned as the hallmark of argument-hood.

Examples of (30)a, (30)b and (30)c are given in (31), (32) and (33) respectively.

[ik wil $\left.[\text { deze spelletje }]_{\mathrm{DP}}\right] \quad$ (I want this game)

(Sarah 2;3.16, week 120).

dat is een paddestoel

(that is a mushroom)

(Sarah 2;3.16, week 120).

(33) (Sarah, 2;5.9 week 128)

(Mother): is die 'afgelopen', het boek?

(is that finished, the book? = have we finished that (one), the book?)

(Sarah): nee, hij is nog niet afgelopen

(no he (=it) is not yet finished = we haven't finished it yet)

The naming function $<+$ ref $>$ of the demonstrative dat blocks its use as a presentational operator. The same blocking effect followed from the new rule that adds an $\mathrm{I}^{\mathrm{o}}$ with EPP effect to all predicates in section 3. The element dat turns from an utterance operator for presentationals into an obligatory marker for naming phrases (DPs). The merely pragmatic intention for applying a content sign as a name is now expressed by a functional category in syntax. The pragmatic $<+$ ref $>$ of previous diagrams can be spelled out as $<+D>$, see (29) above, and (34). 
Pragmatic intention of naming a topic $\Downarrow$

Topic optionally expressed by a gesture sustainable deictic operator $\mathrm{F}^{\mathrm{o}}$ $\Downarrow$

Obligatory presence of $\mathrm{F}^{\mathrm{o}}$ equals $\mathrm{D}^{\mathrm{o}}$ (reference)

It is a remarkable fact that the acquisition graph for systematic D-marking coincides with the graph for free anaphors as (35) shows. See Van Kampen (2003) for more details.

Dutch Sarah: Acquisition of D-marking and $3^{\text {rd }}$ person pronouns

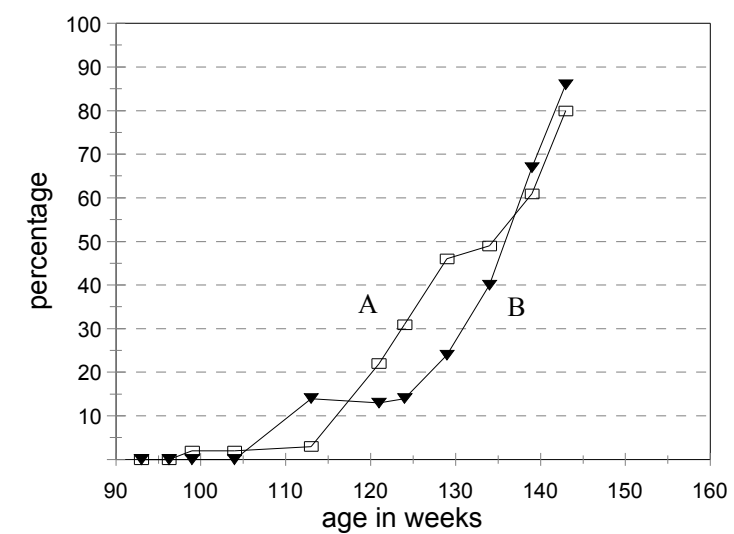

Each measuring point in the graphs represents 2 consecutive files.

Graph A: Noun phrases that realize $\mathrm{D}^{\circ}$ (determiners) in obligatory contexts in $\geq$ two-word utterances

Graph B: Ratio of $3^{\text {rd }}$ person pronouns w.r.t. nouns measured as a percentage of the ratio in the speech of the mother within the same files.

Clearly $<+\mathrm{D}>$ stands for the referential function. As soon as this function is expressed by the functional category $<+\mathrm{D}>$, it becomes possible to use $<+\mathrm{D}>$ independently as a free anaphor in argument position. By free anaphors I mean (full/weak/clitic) pronouns as opposed to bound anaphors (reflexives).

The $<+D>$ of personal pronouns (33) takes the same argument functions as a fully lexicalized DP, see (30)c. Personal pronouns can be used as free anaphors. ${ }^{11}$ Argument structure itself does not really exist without $<+\mathrm{D} /$ case $>$ marking. Before D-marking, arguments are more like parts of a compound. They lack separate referentiality. Argument structure, say Baker's UTAH (Baker 1988:46f), needs <+D/case $>$ marking. The UTAH ( Uniform Theta Assignment Hypothesis) holds that theta roles select a linearly fixed X-bar configuration for the theta-assigning verb and its theta-carrying argument. Such a close relation between argument-hood and referentiality has been argued for by Williams (1994: chapter 6). See Evers \& Van Kampen (2001) and Tracy (2002) for the role of the UTAH in establishing the argument position.

As before with the syntactic operator $<+\mathrm{I}>$, the syntactic operator $<+\mathrm{D}>$ selects a subset of the category-neutral $\mathrm{X}^{\circ}$. The lexical category $<+\mathrm{N}>$ can now be deduced for all elements that appear as the complement of a determiner $\mathrm{D}^{\mathrm{o}}$, see (36).

\footnotetext{
${ }^{11}$ The rise of personal pronouns indicate that the operators from proto-grammar have been reinterpreted as $\mathrm{I}^{\mathrm{O}}$ elements that trigger EPP. See section 3.
} 
(36) a. $\mathrm{X}=><+\mathrm{N}>/$ [case] (morphological context)

b. $\mathrm{X}=><+\mathrm{N}>/ \mathrm{D}[\ldots]$ [ $]$ (phrasal context)

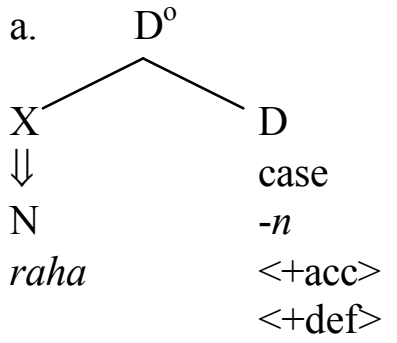

(Finnish, Comrie 1981)

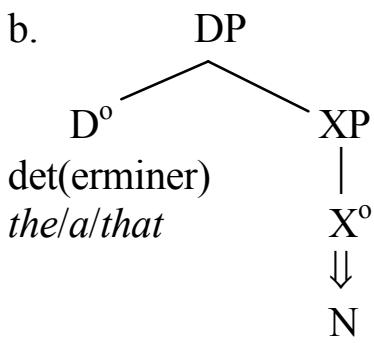

bear

The context-sensitive acquisition rules in (36) demonstrate again how language-specific paradigms lead the learner towards universal properties. Note that my point of view deliberately contradicts the more common position that universal categories would be given and that they allow the identification of the more language-specific arrangements (Chomsky 1995).

I hope that the claims in (6)a-c have been sufficiently supported by quantitative arguments to show their potential. What this type of acquisition research needs most are files of child language that are denser and sufficiently early to make the graphs more detailed for subcategories. Nevertheless, I feel confident about having shown the points in (37)a-c.

(37) a. There is a proto-grammar that still lacks functional structures and syntactic categories. Its structures are situation bound. Proto-grammar starts with pragmatic operators and with content signs $\mathrm{X}^{\mathrm{o}}$ that are category-neutral. They can be used, and are used in child language, as proper names with topic intention and as brand names with characterizing intention.

b. Deictic operators for topic and deictic operators for comment are regularized as Dmarking and I-marking. As soon as I-marking and D-marking have been perceived, the topic-comment of proto-grammar turns into the subject-predicate of real grammar.

c. These functional categories $\mathrm{I}^{\mathrm{o}}$ and $\mathrm{D}^{\mathrm{o}}$ are the crucial bootstraps for category assignment $<+\mathrm{V}\rangle$ and $\langle+\mathrm{N}\rangle$, as a subdivision of the lexicon. The acquisition of language specific devices of $\mathrm{I}^{\mathrm{o}}$ and $\mathrm{D}^{\mathrm{o}}$ are the condition for distinguishing the universal categories $\mathrm{V}$ and $\mathrm{N}$.

The points (6)a-c, repeated as (37)a-c, lead up to the point (6)d discussed in the next section.

\subsection{Lexical mixing and code switching.}

It is a curious fact that children in a bilingual environment succeed to acquire simultaneously more than one grammatical system. No fatal confusion needs to occur. The difference between the phonological representations may keep the two systems sufficiently apart. Yet, more must be involved, since elements from one system may pop up and mix in when the other system is being used. It seems as if both systems are active although one is temporarily tuned down. It reminds of simultaneous translations. Some elements are more likely than others to mix in while the other system is in charge. Our sketch of category acquisition above allows certain plausible predictions. Four types of categories have been distinguished, two in proto-grammar and two in the (beginning) adult grammar. They are listed below with mention 
of their grammatical context condition. The general idea is that an element will be less likely to mix if it is marked by more context conditions.

\section{Context restrictions proto-categories}

Pragmatic operators: highly situation-bound, a syntactic left- or right-hand position Category-neutral X: neither situation-bound nor syntactically restricted (content word)

\section{(38) Context restrictions real categories}

Functional category: situation free, syntactically fully defined

Category-marked X: situation free, syntactically restricted to I- or D-context

(lexical category)

The pragmatic and semantic distinctions within the largely category-free proto-grammar should mix easily, but the syntactically and morphologically restricted categories in the full grammar should not.

It comes as a slight surprise to hear that some of the pivots (Braine's 1963 terminology), labeled here as 'pragmatic operator' and labeled 'predicate' in Deuchar \& Vihman (this volume), are more likely to mix than the content words. An example would be the use of English more in a German two-word construction used in a German context more Apfelsaft ('apple juice'). The following may be relevant. Suppose there is a very young bilingual speaker and he/she switches $15 \%$ of his tokens. The quantitative proportion between operator tokens and content word tokens is, say $40 \%$ operators versus $60 \%$ content words. ${ }^{12}$ One expects then, all things being equal, the return of that proportion $40 \%$ operator mix versus $60 \%$ content word mix. To the extend that operator mixes exceed the $40 \%$ level, they show a higher liability for mixing.

Anyway, the predictions for the real categories (38) are clearer. All categories are now grammatically restricted by phrasal as well as by morphological context. Item specifications for morphological paradigms require more specifications in the lexicon, for example "this noun is masculine, strong inflection, umlaut, plural\}". So, one does not expect that such elements will easily mix into the positions offered by another system. The morphologically strongly embedded $\mathrm{N}$ and $\mathrm{V}$ are so to speak too pretentious about their immediate environment. Phrasal restrictions $((24) /(36) b)$ on the choice of the lexical categories are more easily overruled than morphological restrictions $((24) /(36) a)$. English is a good example. Category conversion (a walk or to walk, a sleep and I sleep) is quite common in English, because the restrictions are phrasal conditions only. Lexical elements from such a system are not particularly shy to enter another syntactic environment. One expects them to mix in easily.

Functional categories, by contrast, are defined by their syntactic environment. They will not mix in at all. If they pop up, the speaker has not mixed in an element from another system. He has code-switched. This leads me to an interpretation of two examples in GawlitzekMaiwald \& Tracy (this volume: example (18)), repeated here as (39).

(39) a. Die Svenjy hat mich gechased and I chased her (The) Svenjey has me prefix-chased and I chased her

b. Clean-st du dein teeth?

$$
\text { Clean }-3^{\text {rd }} \text { sing you your teeth }
$$

\footnotetext{
${ }^{12}$ It is true that operators have a hundred-fold frequency as compared to content signs, remind the figures for Sarah in (14), but this difference in frequency holds for single items (types) not tokens.
} 
Case (39)b is simple. An English content word clean mixes into a German construction. The English verbal morphology is relatively poor and the lexical element at issue clean has no trouble to put on the German verbal morphology instead. The example (39)a is rather intriguing. It is a code-switching on a past participle, but this past participle is in the German predicate final position, where an English past participle would not show up. Moreover, the past participle has the German prefix and the English suffix. When the English content word chase brought in that suffix $(-e d)$ half resembling the German one $(-t)$, it brought in the full English system.

To conclude, evidence from first language acquisition shows that in proto-grammar illocution operators and content elements are not syntactically restricted. In a bilingual situation, a language switch should then be easy. This no longer holds after the acquisition of functional categories and the subsequent categorization of lexical categories. A lexical switch will then have a reflex on the syntactic context which may lead into a code-switching. Beware the functional categories, my child. They will draw you into the other system.

\section{References}

Baker, M.C. (1988) Incorporation. A Theory of Grammatical Function Changing, Chicago: University of Chicago Press.

Bellugi, U. (1967) The Acquisition of the System of Negation in Children's Speech, PhD. dissertation Harvard University.

Blom, E. (2003) From Root Infinitive to Finite Sentence, PhD dissertation Utrecht University

Blom, E. and E, Krikhaar (2002) 'Where to use a nonfinite clause? An experiment on the use of verb forms in early Dutch and English child language', in: J.Costa and J.M. Freitas (eds.) Proceedings of GALA 2001 Palmela, Portugal

Braine, M.D.S. (1963) 'The ontogeny of English phrase structure: the first phase', in: Language 39, 1-13.

Braine, M.D.S. (1976) 'Children's first word combinations', Monographs of the Society for Research in Child Development 41 (Serial no. 164).

Chomsky, N. (1981) Lectures on Government and Binding, Dordrecht: Foris.

Chomsky, N. (1995) The Minimalist Program, Cambridge Mass./London: MIT Press.

Comrie, B. (1981/1987) Language Universal and Linguistic Typology, Oxford/Cambridge: Blackwell, $3^{\text {rd }}$ edition.

Deuchar, M. \& M. Vihman (this volume) 'A radical approach to early mixed utterances'.

Drozd K.F. (1995) 'Child English pre-sentential negation as meta-linguistic exclamatory sentence negation', Journal of Child Language 22: 583-610.

Emonds, J. (1985) A Unified Theory of Syntactic Categories, Dordrecht: Foris.

Evers, A. and J. van Kampen (2001) 'E-language, I-language and the order of parameter setting', UiL OTS Working Papers 00105-S-S, Utrecht University. http://www.let.uu.nl/ Jacqueline.vanKampen/personal/downloadables.htm

Gawlitzek-Maiwald, I. \& R. Tracy (this volume) The multilingual potential in emerging grammars'.

Grimshaw, J. (1991) 'Extended Projection', ms. Linguistics and Cognitive Science Program and Center for Complex Systems, Brandeis University.

Hoekstra, T. \& P. Jordens (1994) 'From adjunct to head', in: T. Hoekstra and B.D. Schwartz (eds.) Language Acquisition Studies in Generative Grammar, Amsterdam/Philadelphia: John Benjamins, 119-149.

Hoekstra, T. \& N. Hyams (1995) 'The syntax and pragmatics of early clause structure', ms. Leiden University \& UCLA. 
Hoekstra, T. \& N. Hyams (1998) 'Aspects of root infinitives', Lingua 106, 81-112.

Hulk, A. (2003) 'Merging scope-particles. Word order variation and the acquisition of aussi and ook in a bilingual context', in: Chr. Dimroth \& M. Starren (eds.) Information Structure and the Dynamics of Language Acquisition, Amsterdam: John Benjamins, 211-234.

Hyams, N (1986) Language Acquisition and the Theory of Parameters, Dordrecht: Reidel.

Jordens, P. (2002) 'Finiteness in early child Dutch', Linguistics 40 (4), 687-765.

Kampen, J. van (1987) 'De ontwikkeling van ontkenningen in de kindertaal (The development of negation in child language)', ms. Utrecht University.

Kampen, J. van (1997) First Steps in Wh-movement, Delft: Eburon.

Kampen, J. van (2001a) 'Review of Becker 'The Development of the Copula in Child English', in: GLOT International 7-5, URL http://www.linguistlistplus.com.

Kampen, J. van (2001b) 'Bootstraps at two for lexicon and discourse', in: Proceedings of ELA (Early Lexicon Acquisition), Lyon, December 5-8, http://www.let.uu.nl/ Jacqueline.vanKampen/personal/downloadables.htm

Kampen, J. van (2003) 'The acquisition of the standard EPP in Dutch and French', ms.Utrecht University http://www.let.uu.nl/ Jacqueline.vanKampen/personal/downloadables.htm

Kampen, J. van (to appear) 'Learnability order in the French pronominal system', to appear in: R. Bok-Bennema \& B. Hollebrandse (eds.) Selected Papers from Going Romance 2002. Amsterdam Studies in the Theory and History of Linguistic Science.

Lebeaux, D. (1988) Language Acquisition and the Form of Grammar, PhD. dissertation University of Massachusetts.

Lyons, J. (1977) Semantics, Cambridge: Cambridge University Press.

Lyons, J. (1979) 'Deixis and anaphora', in: T. Myers (ed.) The Development of Conversation and Discourse, Edinburgh: University Press, 88-103.

MacWhinney, B (1991) The CHILDES Project: Tools for analyzing talk, Hillsdale New York: Lawrence Erlbaum.

Marantz, A. (1997) 'No escape from syntax: Don't try morphological analysis in the privacy of your own lexicon', in A. Dimitriadis, L. Siegel, et al. (eds.) University of Pennsylvania Working Papers in Linguistics 4.2, 201-225.

Penner, Z., R. Tracy and J. Weissenborn (2000) 'Triggering object scrambling', in: S.M. Powers and C. Hamann (eds.) The Acquisition of Scrambling and Cliticization, Dordrecht: Kluwer Academic Publishers, 127-164.

Pinker, S. (1984) Language Learnability and Language Development, Cambridge Mass./London: Harvard University Press.

Poeppel, D. \& K. Wexler (1993) 'The full competence hypothesis of clause structure in early German', Language 69.1, 1-33.

Powers, S. (1996) 'MAPping phrase markers', in: Ch. Koster and F. Wijnen Proceedings of GALA (Groningen Assembly on Language Acquisition), 303-313.

Powers, S. and Lebeaux, D. (1998) 'More data on DP acquisition', in: N.D. Dittmar \& Z. Penner (eds.) Issues in the Theory of Language Acquisition, Bern: Peter Lang, 37-77.

Radford, A. (1990) Syntactic Theory and the Acquisition of English Syntax: the Nature of Early Child Grammars of English, Oxford: Basil Blackwell.

Radford, A. (1996) 'Towards a structure-building model of acquisition', in: H. Clahsen (ed.) Generative Perspectives on Language Acquisition, Amsterdam: John Benjamins, 43-89.

Rizzi, L. (1994). Early null subjects and root null subjects. Language acquisition studies in generative grammar. T. Hoekstra and B. Schwarz. Amsterdam/Philadelphia, John Benjamins: 151-176.

Rizzi, L. (2002) 'On the grammatical basis of language development: A case study', ms. University of Siena. 
Roeper, T. (1992) 'From the initial state to V2: Acquisition principles in action', in: J. Meisel (ed.) The Acquisition of Verb Placement. Dordrecht: Kluwer Academic Publishers, 333-370.

Santelmann, L.M. (1995) The Acquisition of Verb Second Grammar in Child Swedish: Continuity of Universal Grammar in Wh-questions, Topicalization and Verb Raising, PdD. dissertation Cornell University.

Stassen, L. (1997). Intransitive Predication. Oxford Studies in Typology and Linguistic Theory. New York: Oxford University Press.

Tracy, R. (1994) 'Raising questions: formal and functional aspects of the acquisition of whquestions in German', in: R. Tracy \& E. Lattey (eds.) How Tolerant is Universal Grammar: Essays on Language Learnability and Language Variation, Tübingen: Niemeyer. 1-34.

Tracy, R. (2002) 'Growing (clausal) roots: all children start out (and may remain) multilingual', Linguistics 40 (4), 653-686.

Wexler, K. (1998) 'Very early parameter setting and the unique checking constraint: A new explanation of the optional infinitive stage', Lingua 106, 23-79.

Williams, E. (1994) Thematic Structure in Syntax, MIT Press, Cambridge Mass.

Wittgenstein, L. (1953/1975) Philosophische Untersuchungen, Frankfurt am Main: Suhrkamp, $3^{\text {rd }}$ edition. 